\title{
Preparation of Thick Silica Films by Combined Sol-Gel and Electrophoretic Deposition Methods
}

\author{
Kazuo KISHIDA, Masahiro TATSUMISAGO and Tsutomu MINAMI \\ Department of Applied Materiats Science, Osaka Prefecture University, 1-1, Gakuen-cho, Sakai-shi, Osaka 593

\begin{abstract}
ゾル-ゲル法と電気泳動法を組み合わせたコーティング手法によるシリカ厚膜の作製
岸田和雄・辰巳砂昌弘・南努

大阪府立大学工学部機能物質科学科, 593 堺市学園町 1-1
\end{abstract}

[Received October 18, 1993; Accepted January 27, 1994]

\begin{abstract}
Homogeneous, thick silica films composed of fine particles were prepared in a short time by using an electrophoretic deposition technique combined with the sol-gell method. Electrophoretic deposition was carried out using the silica sols derived from tetraethoxy= silane hydrolyzed with water of a variety of $\mathrm{pH} ; \mathrm{EtOH}$, $i$-PrOH, and $n$-PrOH were used as a solvent. In the case of $\mathrm{pH}=11.7$ and a solvent of $\mathrm{EtOH}$, the maximum coating weight was attained at an applied voltage of $140 \mathrm{~V}$ and the thickness of the fillm was about $17 \mu \mathrm{m}$. The surface of this coating film was found to be homogeneous and smooth by SEM observation. The coating weight was roughly proportional to the charge density with nearly the same slope independent of the kind of solvents.
\end{abstract}

Key-words : Sol-gel, Electrophoretic deposition, Thick films, Silica, Coating

\section{Introduction}

There are a variety of preparation procedures of oxide films; physical vapor deposition methods like vacuum evaporation and sputtering have widely been used. Those methods which involve a process through the vapor phase sometimes cause a deviation of chemical composition between the starting materials and resultant films. In addition, those methods require an expensive vacuum apparatus.

The sol-gel method, in which a substrate is immersed in sols usually prepared from metal-alkoxide solutions and then withdrawn at a constant speed to be coated with a thin film, is one of the excellent techniques to produce homogeneous ceramic films by use of a quite simple apparatus compared to the physical vapor deposition techniques.1 ${ }^{1-3)}$ However, it has been pointed out that the sol-gel method is difficult to produce thick films $(>2-3 \mu \mathrm{m})$. When the thickness becomes more than $0.2 \mu \mathrm{m}$ at one time coating, the films obtained tend to be cracked.

On the other hand, electrophoretic deposition, in which fine particles $(0.2-40 \mu \mathrm{m}$ in diameter) in suspension migrate toward the electrodes to deposit when an electric field is applied across them, is known as one of the preparation procedures for thick films. This technique has widely been applied in various fields, for example preparation of phosphors as a display, ${ }^{4)}$ solid electrolytes for electrochromic display, ${ }^{5)}$ superconductors, ${ }^{6)}$ and ferroelectric materials. ${ }^{7)}$ The main advantage of the electrophoretic deposition is the fact that homogeneous thick films can be prepared on various substrates with a complex shape in much shorter time compared to other film preparation processes. Film thickness can easily be controlled by varying the applied voltage, the electrophoresis time and the concentration of the suspensions.

However, the preparation of stable suspensions with fine and uniform particles, which is essential to obtain excellent thick films, is difficult. For example, when raw materials are ground by using a conventional ball mill, the particles are not uniform, the size distribution is broad, and the smallest particle size is at most $0.2 \mu \mathrm{m}$. The sol-gel method can produce uniform and spherical particles and also reduce particle size limits by more than one order of magnitude (approximately up to $0.01 \mu \mathrm{m}$ ).8) Finer particles are expected to have more intimate contact to each other and to a substrate, giving a dense and uniform coating layer. Although coating techniques combining the sol-gel method with the electrophoretic deposition seem very promising to obtain ceramic thick films, there have been few studies on this fascinating subject so far. ${ }^{9)-12)}$

In this paper, we report the preparation procedures of homogeneous thick films of silica in a short time by means of an electrophoretic deposition technique using uniform particles derived from the solgel method.

\section{Experimental}

Silica sols were produced under the basic conditions, because silica particles can be formed in the silica sols. Reagent grade chemicals of tetraethoxysilane $\left(\mathrm{Si}(\mathrm{OEt})_{4}\right)$, ethanol $(\mathrm{EtOH})$, isopropyl alcohol ( $i$-PrOH $), n$-propyl alcohol $(n-\mathrm{PrOH})$ and ammonium hydroxide $\left(\mathrm{NH}_{4} \mathrm{OH}\right)$ (Wako Pure Chemical Industries, Ltd., Osaka, Japan) were used as starting materials. Figure 1 shows the flow chart for the 


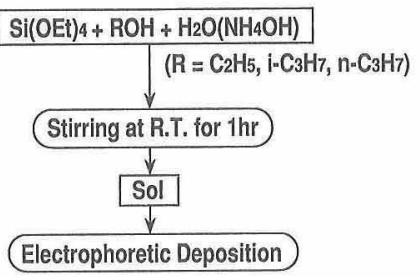

Fig. 1

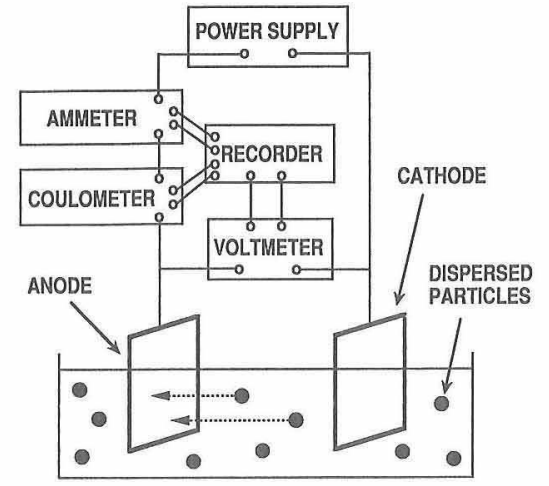

Fig. 2

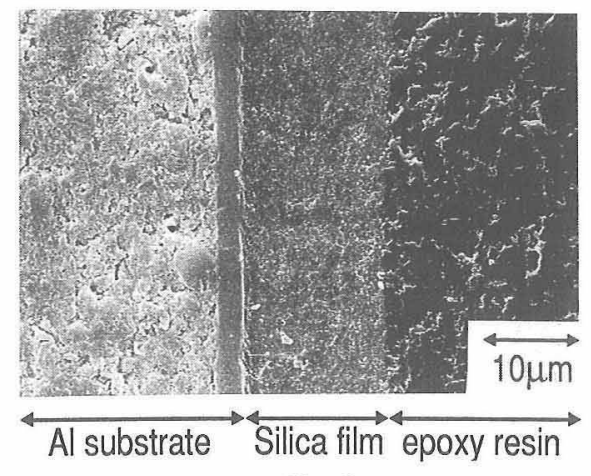

Fig. 3

Fig. 1. Preparation procedure of the silica sols for subsequent electrophoretic deposition.

Fig. 2. Schematic drawings of the setup for the electrophoretic deposition system used in the present study.

Fig. 3. SEM photograph of the sectional view of the silica film formed by the electrophoretic deposition at an applied voltage of $140 \mathrm{~V}$; EtOH was used as a solvent.

preparation procedure of the silica sols for the electrophoretic deposition. $\mathrm{Si}(\mathrm{OEt})_{4}$ was diluted with alcohol (EtOH, $i-\mathrm{PrOH}$, or $n$-PrOH) as a solvent and hydrolyzed with water of a variety of $\mathrm{pH}$ which was adjusted with $\mathrm{NH}_{4} \mathrm{OH}$. The molar ratios of alcohols and $\mathrm{H}_{2} \mathrm{O}$ to $\mathrm{Si}(\mathrm{OEt})_{4}$ were both fixed at 10 . Two types of aluminum plates were used as coating substrates. One is a "non-treated" substrate which was only washed with $i$-PrOH in an ultrasonic bath and the other is an "anodized" substrate; the anodization of the substrates was carried out in the following procedures based on JIS H9500. Aluminum substrates were cleaned with $i$-PrOH in an ultrasonic bath and degreased with $15 \mathrm{wt} \% \mathrm{H}_{2} \mathrm{SO}_{4}$ for 2 min at $60^{\circ} \mathrm{C}$. After being rinsed with ion-exchanged water, the substrates were oxidized under a current density of $13 \mathrm{~mA} / \mathrm{cm}^{2}$ for $30 \mathrm{~min}$ and then washed with ionexchanged water. Pores of anodized oxide films were not sealed.

Figure 2 illustrates the setup used for the electrophoretic deposition. Two aluminum substrates $(40 \times 25 \times 1 \mathrm{~mm})$ were placed parallel with a separation distance of $1.5 \mathrm{~cm}$. The substrates were immersed in the sol to a depth so as to give $5 \mathrm{~cm}^{2}$ of active surface area. A constant DC voltage was applied across the two substrates for $10 \mathrm{~min}$ by using a power supply (Takasago, Ltd., GPV 0650-0.5), causing in the migration of negatively charged colloidal particles toward the anode. The voltage, the current, and the number of coulombs consumed were monitored by using an electronic voltmeter (Toa Electronics Ltd., PM-12), an electrometer (Takeda Riken Industry Co., Ltd., TR-8651), and a coulometer (Nichia, N-CR646), respectively, throughout the electrophoresis process.

Coatings obtained were dried in a desiccator over silica gel for one night before weighing. The weight of coating layers on the aluminum plate anode was measured with a microbalance (Mettler, M5SA) before and after coating. A scanning electron micro- scope (SEM; JEOL, JSM-5300) was used for the observation of film morphology and the estimation of the film thickness.

\section{Results and discussion}

We first examined the effect of the pretreatment of $\mathrm{Al}$ substrates on the adhesion between the coating films and the substrates. Table 1 lists the maximum weights of the deposited films adhered tightly to the substrates with and without anodization treatments; $n$-PrOH, $i$-PrOH and EtOH were used as a solvent. Additional anodization reactions were not observed during electrophoretic deposition in such a basic condition. In any solvent, the maximum weight of the coating films on the anodized substrates is larger than that on non-pretreated substrates, indicating that the anodization of substrates apparently improves the adhesion. Such a good adhesion probably relates to the porous structure of the aluminum oxide layers formed on the substrates by anodization. ${ }^{13)}$ The anchor effect of these pores may produce the strong mechanical adhesion. Since the anodization of the substrates was found to be effective to deposit large amounts of electrophoretic silica. coatings on the substrate, we concentrate on the coatings on the anodized substrates for further discussion.

Table 1. Maximum Weight of Silica Coating Obtained Using Several Alcohols on Anodized and Non-Treated Al Substrates. The Composition of the Starting Solution was $1 \mathrm{Si}(\mathrm{OEt})_{4}$. $10 \mathrm{ROH} \cdot 10 \mathrm{H}_{2} \mathrm{O}(\mathrm{pH}=11.7)$. The Values in Parentheses Indicate the Applied Voltage

\begin{tabular}{cccc}
\hline \multirow{2}{*}{ treatment } & \multicolumn{3}{c}{ maximum weight $/ \mathrm{mg} \mathrm{cm}^{-2}$} \\
\cline { 2 - 4 } n-PrOH & $\mathrm{i}-\mathrm{PrOH}$ & $\mathrm{EtOH}$ \\
\hline anodized & $\begin{array}{c}8.32 \\
(300 \mathrm{~V})\end{array}$ & $\begin{array}{c}2.66 \\
(200 \mathrm{~V})\end{array}$ & $\begin{array}{c}2.69 \\
(140 \mathrm{~V})\end{array}$ \\
non-treated & $\begin{array}{c}4.79 \\
(160 \mathrm{~V})\end{array}$ & $\begin{array}{l}1.46 \\
(60 \mathrm{~V})\end{array}$ & $\begin{array}{c}0.35 \\
(20 \mathrm{~V})\end{array}$ \\
\hline
\end{tabular}


Figure 3 shows a scanning electron microscope (SEM) photograph of the sectional view of the silica film prepared by using EtOH as a solvent under an applied voltage of $140 \mathrm{~V}$; as seen from Table 1 the silica film prepared under this condition has the maximum weight gain. The SEM photograph shows the three layers, aluminum substrate, silica film, and epoxy resin for embedding the film. The film is apparently uniform and thick.

The thickness obtained from the photograph and the calculated density of the silica film in addition to the coating weight are listed in Table 2. The thickness is about $17 \mu \mathrm{m}$ and the calculated density of this film is about $1.6 \mathrm{~g} / \mathrm{cm}^{3}$. Since the density of silica gel monolith prepared under basic condition was reported to be about $\left.0.65 \mathrm{~g} / \mathrm{cm}^{3},{ }^{14}\right)$ it is concluded that this film is denser than the bulk silica gel produced by the usual sol-gel method.

Figure 4 shows the relation between the weight of the coating films and the applied voltage during electrophoretic deposition for the silica sols with a variety of $\mathrm{pH}$ (the solvent was $\mathrm{EtOH}$ ). In this figure, the symbol $\times$ indicates the voltage at which the electrophoretic films began to peel off; these voltages were basically reproduced in the present study. The values of the ordinate at $0 \mathrm{~V}$ mean the weight of the coating films obtained by the dip-coating method. The coating weight is increased with an increase in the applied voltage; the slope becomes steeper when the $\mathrm{pH}$ of the sols is increased, although the coating weight by the electrophoretic deposition is almost the same as that by the dip-coating at $\mathrm{pH}=11.3$. The voltage at which the coating films began to peel off

Table 2. Coating Weight, Thickness, and Calculated Density of the Silica Film of which the Sectional View is Shown in Fig. 3

\begin{tabular}{ccc}
\hline weight $/ \mathrm{mg} \mathrm{cm}^{-2}$ & thickness $/ \mu \mathrm{m}$ & density $/ \mathrm{g} \mathrm{cm}^{-3}$ \\
\hline 2.69 & 17 & 1.6 \\
\hline
\end{tabular}

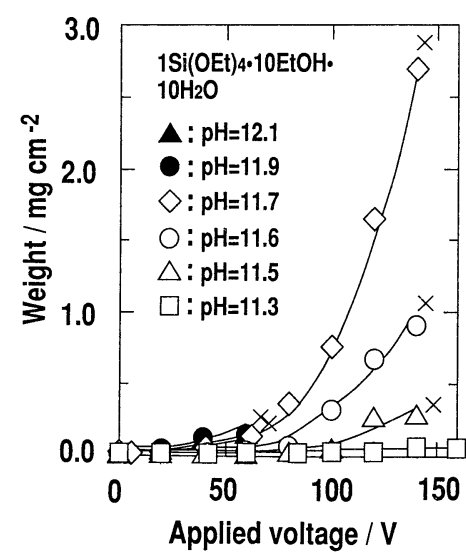

Fig. 4. Weights of the silica films obtained by the electrophoresis of silica sols with a variety of $\mathrm{pH}$ against the applied voltage. EtOH was used as a solvent. depends on the $\mathrm{pH}$ of the sols. In the $\mathrm{pH}$ range of 11.5-11.7 (open symbols), the limiting voltage is as high as $140 \mathrm{~V}$ and the maximum coating weight is increased with an increase in the $\mathrm{pH}$ of the sols; when $\mathrm{pH}=11.7$ the weight has the largest values of 2.69 $\mathrm{mg} / \mathrm{cm}^{2}$ at $140 \mathrm{~V}$. On the other hand, when the $\mathrm{pH}$ is larger than 11.7 (solid circles and triangles), the deposited films peeled off at lower voltage of about $60 \mathrm{~V}$.

Figure 5 shows the morphology of electrophoretic deposition films prepared at $\mathrm{pH}=11.3$ (a), $\mathrm{pH}=11.7$ (b) and $\mathrm{pH}=12.1$ (c). At $\mathrm{pH}=11.3$ the surface of the coating films appears very smooth. This observation must reflect the fact that the coating films were made up of ultra-fine particles of which the size could not be determined by the SEM (below 0.05 $\mu \mathrm{m})$. Similarly at $\mathrm{pH}=11.7$ (b) the surface is very homogeneous and smooth because the coating films were made up of microparticles of about $0.1 \mu \mathrm{m}$ in diameter as determined by the SEM observation. On the other hand, when $\mathrm{pH}=12.1$ (c), the surface is not so smooth owing to relatively large constituent particles of about $0.4 \mu \mathrm{m}$ in diameter, as shown in Fig. 5(d) which is an enlarged photograph of Fig. 5 (c). From the SEM observation of the coating films prepared at a variety of $\mathrm{pH}$, it is concluded that the films are basically constructed by aggregated fine particles, of which the size increases with an increase in $\mathrm{pH}$ of the starting sols. This tendency is consistent with the fact that in the sol-gel method the $\mathrm{pH}$ increase under basic hydrolysis condition increases the particle size in sols. ${ }^{15)}$ Since the mobility of the particles in sols generally becomes higher with an increase in the particle size, ${ }^{16)}$ it is understood that the coating weight increases with an increase in $\mathrm{pH}$ at a given applied voltage.

Peeling off of the coating films occurs at both lower and higher $\mathrm{pH}$ than 11.7 in spite of the small weight as shown in Fig. 4. In other words, peeling off of the coating films occurs easily when the size of particles deposited is too small and too large as seen in Fig. 5. In the low $\mathrm{pH}$ region, the coating films cracked during the drying process and peeled off from the substrates.

The peeling process in both $\mathrm{pH}$ regions is explained as follows. In drying process of gels the capillary pressure $C_{\mathrm{p}}$ is produced as represented by Eq. (1)

$$
C_{\mathrm{p}}=2 \gamma \cos \theta / D
$$

where $\gamma$ is the surface tension of the solvent, $\theta$ is the contact angle of the receding meniscus within the open pore and $D$ is the pore size. ${ }^{1)}$ In the low $\mathrm{pH}$ region, the particles are small and therefore the pore size $D$ in the secondary particles is expected to be small. When the pore size $D$ is small, the capillary pressure $C_{\mathrm{p}}$ must become large according to Eq. (1). Since the tensile stress occurs in the surface layer by this capillary pressure $C_{\mathrm{p}}$, the coating films tend to crack and peel off from the substrates under the low 


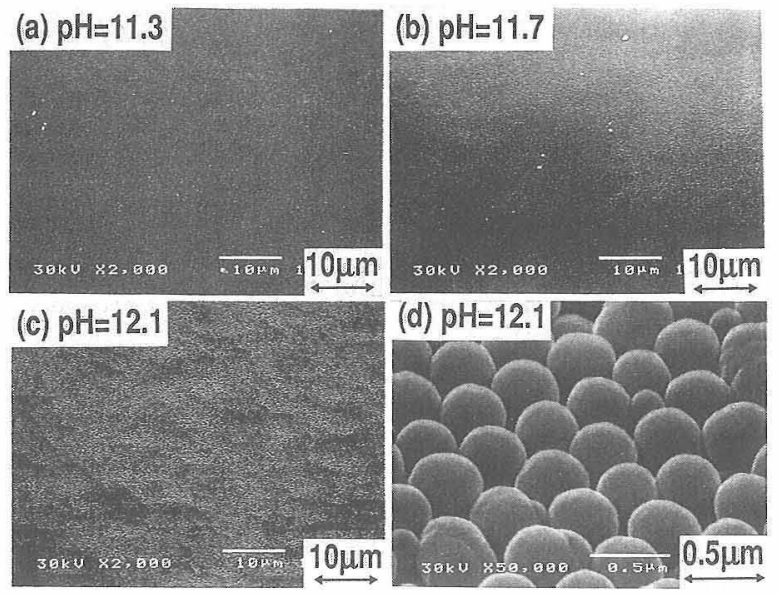

Fig. 5

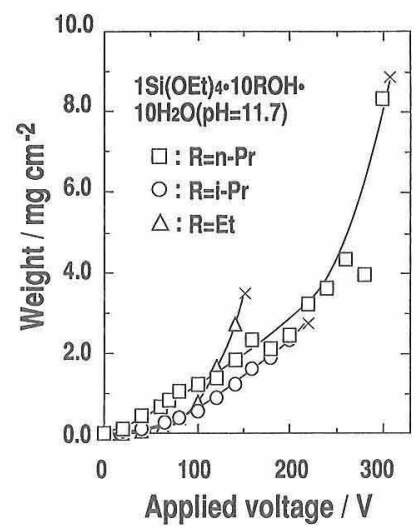

Fig. 6

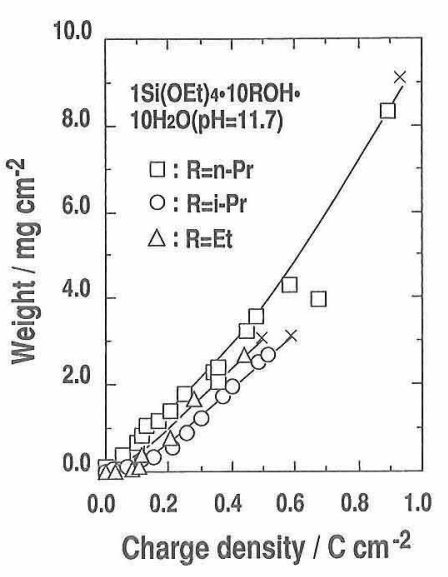

Fig. 7

Fig. 5. SEM photographs of the silica films formed by electrophoretic deposition at a variety of $\mathrm{pH}$; the composition of the starting solution was $1 \mathrm{Si}(\mathrm{OEt})_{4} \cdot 10 \mathrm{EtOH} \cdot 10 \mathrm{H}_{2} \mathrm{O}$ in molar ratio. (a) $\mathrm{pH}=11.3$, (b) $\mathrm{pH}=11.7$, (c) and (d) $\mathrm{pH}=12.1$.

Fig. 6. Weights of the silica films formed by the electrophoretic deposition against the applied voltage. $n$-PrOH, $i$-PrOH, and EtOH were used as a solvent.

Fig. 7. Weights of the silica films formed by the electrophoretic deposition against the charge density. $n$-PrOH, $i$-PrOH, and EtOH were used as a solvent.

$\mathrm{pH}$ condition.

In the high $\mathrm{pH}$ region, on the other hand, the coating films were almost free from cracks and peeled off at the interface between the films and the substrates. In this case, the films composed of large particles probably have large pores. When the coating films become porous, the contact area between the coating films and the substrates would become small. In other words, adhesion of the coating films to the substrates become weak, and thus the coating films tend to peel off at the interface between the films and the substrates. The decrease in the anchor effect also must be the factor of peeling off.

Figure 6 shows the relationship between the weight of the coating films and the applied voltage during electrophoretic deposition for the silica sols with a variety of solvents; the $\mathrm{pH}$ of $\mathrm{H}_{2} \mathrm{O}$ added was kept constant at 11.7. In this figure, the symbol $\times$ indicates the voltage at which the coating films began to peel off, as in the case of Fig. 4. Different solvents gave different values of $x$, indicating that the adhesiveness of the films to the substrates depends on the kind of solvents. The use of $n-\mathrm{PrOH}$ as a solvent gave the maximum weight of the coating films of $8.32 \mathrm{mg} / \mathrm{cm}^{2}$, which was much larger compared to the case for the use of EtOH or $i$-PrOH. The thickness of the deposited film prepared using $n$-PrOH was about $50 \mu \mathrm{m}$ from SEM observation of the sectional view of the film; the density of this film calculated is about $1.6 \mathrm{~g} / \mathrm{cm}^{3}$, which is almost the same as that obtained from EtOH as a solvent (see Table 2).

Figure 7 shows the relationship between the weight of the coating films and the charge density during electrophoretic deposition for the silica sols; this figure has been drawn by changing the abscissa in Fig. 6 from the applied voltage to the charge densi- ty. In all cases of solvents, the coating weight is basically proportional to the charge density with nearly the same slope of the plots. Therefore, the coating weight is thought to be mainly determined by the number of coulombs passing across the electrodes during the electrophoresis in any solvent. The rate of electrophoretic deposition is determined to be 7.68 $\mathrm{mg} / \mathrm{C}$ in the case of $n-\mathrm{PrOH}$ used as a solvent.

\section{Conclusions}

The coating procedure combining the electrophoretic deposition with the sol-gel method was found to be useful for the preparation of thick silica films; e.g., the coating weight had a maximum of $2.69 \mathrm{mg} / \mathrm{cm}^{2}$, which corresponded to a thickness of $17 \mu \mathrm{m}$, at an applied voltage of $140 \mathrm{~V}$ when $\mathrm{EtOH}$ was used as a solvent and the $\mathrm{pH}$ value was 11.7. For all solvents, the maximum coating weight occurred at $\mathrm{pH}=11.7$. The surface of the coating films prepared using $\mathrm{EtOH}$ and water of $\mathrm{pH}=11.7$ was found to have homogeneous and smooth surface because they were made up of spherical microparticles of about $0.1 \mu \mathrm{m}$ in diameter. In the $\mathrm{pH}$ ranges of 11.311.6, although the surface of the coating films was smooth, the films tended to be cracked. On the other hand, when the $\mathrm{pH}$ was larger than 11.7, the coating films, the surface of which was not so smooth, peeled off at lower voltage of about $60 \mathrm{~V}$. The adhesion of the films to the substrates and the thickness depended on the kind of solvents; the largest thickness of $50 \mu \mathrm{m}$ was obtained when $n$-PrOH was used as a solvent. In any case of solvents used, the coating weight was roughly proportional to the charge density for the electrophoresis.

This coating technique has also been useful to prepare thick silica films on a stainless steel substrate 
with no pretreatments. The details will be published elsewhere.

Acknowledgment The present study was partly supported by the Grant-in-Aid from the Ministry of Education, Culture and Science of Japan.

\section{References}

1) C. J. Brinker, A. J. Hurd, G. C. Frye, P. R. Schunk and C. S. Ashley, J. Ceram. Soc. Japan., 99, 862-77 (1991).

2) N. Tohge, A. Matsuda and T. Minami, J. Am. Ceram. Soc., 70, C13-15 (1987).

3) S. Sakka, K. Kamiya, K. Makita and Y. Yamamoto, J. NonCryst. Solids, 63, 223-35 (1984).

4) J. Mizuguchi, K. Sumi and T. Muchi, J. Electrochem. Soc., 130, 1819-25 (1983).

5) K. Kuwabara, K. Sugiyama and M. Ohno, Solid State Ionics, 44, 313-18 (1991).

6) H. Nojima, H. Shintaku, M. Nagata and M. Koba, J. J. Appl. Phys., 30, L1166-68 (1991).
7) S. Sugiyama, A. Takagi and K. Tsuzuki, J. J. Appl. Phys., 30, 2170-73 (1991).

8) G. L. Messing and W. T. Minehan, J. Ceram. Soc. Japan, 99, 1036-46 (1991).

9) W. J. Dalzell and D. E. Clark, Ceram. Eng. Sci. Proc., 7, 1014-26 (1986)

10) D. E. Clark, W. J. Dalzell and D. C. Folz, Ceram. Eng. Sci. Proc., 9, 1111-18 (1988).

11) H. Schmidt and H. Wolter, J. Non-Cryst. Solids, 121, 428-35 (1990).

12) S. Ito, T. Nagai, N. Miyazawa, S. Ishida and N. Takatori, The Abstract of 81st Annual Meeting of The Surface Finishing Society of Japan (1990) pp. 227-28.

13) "Denkikagakubinran", Ed. by The Electrochemical Society of Japan, Maruzen, Tokyo (1985) pp. 365-69.

14) T. Adachi, S. Sakka and M. Okada, Yogyo-Kyokai-Shi, 95, 970-75 (1987).

15) Y. Azuma, Y. Tajima, N. Ohshima and K. Suehiro, YogyoKyokai-Shi, 94, 559-63 (1986).

16) K. Ogino, I. Kuronuma, Y. Nishimura and H. Takahashi, Nippon Kagaku Kaishi, 462-64 (1978). 